\title{
Providing respiratory support with nasal high flow therapy - A narrative review
}

\author{
Jane O Donnell* \\ Jane O Donnell, Massey University, Albany Campus, Private Bag, Auckland, New Zealand
}

\begin{abstract}
More than fifteen years ago clinicians' saw the introduction of a new form of noninvasive respiratory support which is now commonly known as Nasal High Flow (NHF) therapy. Today this therapy is used throughout hospitals and, in the home settings. This narrative review of the evidence will characterize: NHF mechanisms of action, therapeutic efficacy, contemporary delivery, and strategies for clinical applications.
\end{abstract}

\section{Introduction}

Since the 1940's the ubiquitous conventional oxygen therapy (COT) has been in use providing both limited flows and concentrations of unconditioned supplemental oxygen. In reality these cannulas have several inherent limitations.

More than fifteen years ago clinicians' saw the introduction of a new form of noninvasive respiratory support now commonly known as Nasal High Flow (NHF) therapy. Today this therapy is used throughout hospitals and in the home settings. This therapy was designed for use within conjunction with specially designed nasal cannula and medical humidifiers. These humidifiers are capable of conditioning the delivered gases, thus fully humidifying $\left(100 \%\right.$ saturated with $\left.\mathrm{H}_{2} \mathrm{O}\right)$ and heating these gases to body temperature $\left(370^{\circ} \mathrm{C}\right)$. Consequently, the discomfort and drying of upper airway mucosa seen with COT is now offset. This therapy had first become a standard of care for infants, children, and preterm neonates with flows of $>2 \mathrm{~L} / \mathrm{min} / \mathrm{kg}$ demonstrating a distending pressure akin to nasal CPAP; and today NHF is in use for adults.

Therapeutic flows for adults are in the 10 to $60 \mathrm{~L} / \mathrm{min}$ range; with an option to independently blend air/ $\mathrm{O}_{2}$ thus reliably titrating the $\mathrm{FiO}_{2}$ delivered between 21 to $100 \%$. This change in practice has been driven by the number of confirmed clinical benefits seen compared to conventional respiratory therapy. There is considerable reliable published evidence which substantiates the proposed mechanisms of action. The efficacy of this therapy across a variety of clinical applications and settings has been confirmed, however further research is warranted. This review will characterize: NHF mechanisms of action, therapeutic efficacy, contemporary delivery, and strategies for clinical applications.

\section{Nasal high flow mechanisms of action}

The efficacy of this therapy has been demonstrated through the interplay of a series of mechanisms which are distinct to NHF.

\section{Respiratory support}

Many physiological benefits have been demonstrated with the application of NHF therapy, both in healthy volunteers, and those with acute and chronic illness. The physiological effects of NHF on gas exchange, inspiratory effort, minute ventilation (MV), lung volume, dynamic compliance, transpulmonary pressure, work of breathing and pulmonary homogeneity have been assessed both with standard clinical, and additional advanced measures, such as trans esophageal pressure, electrical impedance, respiratory inductance plethysmography and ultrasound $[1,2]$.

It is accepted that NHF improves breathing efficiency as demonstrated by an increase in tidal volume and reduction in respiratory rate, at a constant minute volume [3,4]. Mauri $\mathrm{T}$ et al. [1] considered the use of NHF in patients with acute hypoxemic respiratory failure. NHF improved oxygenation; reduced the patient's effort; reduced the minute ventilation needed to obtain a physiological $\mathrm{PaCO}_{2}$ level; increased the end-expiratory lung volume; and improved dynamic compliance, trans pulmonary pressure, and ventilation homogeneity. These outcomes might confirm the clinical efficacy of NHF therapy.

Itagaki $\mathrm{T}$ et al. [2] evaluated levels thoracoabdominal asynchrony using respiratory inductance plethysmography. Thoracoabdominal asynchrony was improved with NHF compared to COT. Additionally, respiratory rate and minute volume were lower with $\mathrm{NHF}$, whilst $\mathrm{PaCO}_{2}$ and tidal volume remained unchanged.

\section{Washout of the anatomical dead space}

NHF therapy continuously flushes the dead space volume of expired $\mathrm{CO}_{2}$ (normally present in the nasopharynx) much like tracheal gas insufflation [5]. The $\mathrm{CO}_{2}$ flushing effect is flow dependent. This effect then optimizes the proportion of the potential minute ventilation available for gaseous exchange. More specifically, the turbulence flushes $\mathrm{CO}_{2}$ from the nasopharynx, augmenting respiratory efficiency by reducing the fraction of inspired $\mathrm{CO}_{2}$, whilst raising $\mathrm{FiO}_{2}$. The flushed dead space is then filled with $\mathrm{O}_{2}$ ready for the next inspiration. It this this mechanism that is often thought to drive the both the reductions

${ }^{\star}$ Correspondence to: Jane O Donnell, Massey University, Albany Campus, Private Bag, Auckland, New Zealand, E-mail: Jane.ODonnell@fphcare.co.nz

Key words: nasal high flow therapy

Received: June 11, 2019; Accepted: July 02, 2019; Published: July 05, 2019 
in respiratory rate and work of breathing often seen. This effect is correlated with increases in NHF flow as opposed to increases in pressure [6]. Given the fact that NHF is an open system (non-sealed) the volume of dead space flushed cannot be precisely determined.

\section{Delivery of a dynamic level of positive pressure}

A low level dynamic positive pressure effect within the nasopharyngeal and esophageal anatomy has been demonstrated in adults, infants and neonates [7-13]. This phenomenon has been confirmed both in studies of both healthy and non-healthy participants $[7,8]$ in patients with stable COPD and idiopathic pulmonary fibrosis [9] and post cardio thoracic surgery [10-12]. Corley A et al. [11] evaluated both the pressure effect and end-expiratory lung volume using electrical lung impedance tomography. The research found that end-expiratory lung volume was greater with NHF, than with COT; which suggests an association between the NHF pressure effect and enhanced lung volumes.

The pressure generated by NHF therapy is dynamic it varies across the breath cycle. There is a demonstrated peak at end expiration due to the resistance generated against the incoming flow. During inspiration a low level of pressure exists which provides a small amount of inspiratory assistance which may counterbalance auto-PEEP (through the aforementioned end expiration pressure effect). This phenomenon is especially relevant for patients with high levels of intrinsic PEEP, for example, in COPD. The pressure levels seen are variable, NHF is an open (non-sealed) system, and the size of the cannula relative to the nares has an effect as does individual lung compliance.

The pressure recorded during breathing with NHF correlates linearly with the NHF flow rate and is significantly higher when mouths are closed. Parke RL et al. [12] observed in adults, that for each increase of $10 \mathrm{~L} / \mathrm{min}$ flow rate the mean airway pressure increased by $0.69 \mathrm{~cm}$ $\mathrm{H}_{2} \mathrm{O}(p, .01)$. When subjects breathed with their mouths closed the pressure increased by $0.35 \mathrm{~cm} \mathrm{H}_{2} \mathrm{O}(p, .03)$ [12]. For infants and neonates, the pressure seen is approximate to that seen with nasal CPAP $[13,14]$.

\section{Supplemental oxygen}

In some circumstances NHF therapy with air alone is thought to be able to demonstrate beneficial effects, however if supplemental $\mathrm{O}_{2}$ is required there is the option to titrate it in. For patients with a high inspiratory flow demand COT is often unable to meet the required flow needs, therefore room air is entrained diluting the delivered $\mathrm{FiO}_{2}$. This entrainment varies breath by breath (as does the inspiratory flow demand) so the actual concentration of delivered $\mathrm{O}_{2}$ is unknown which could precipitate either a hyperoxic or a hypoxic event. In contrast, and in many cases, NHF has the ability to meet or exceed the inspiratory flow demand therefore less entrainment of room air occurs, as a result the desired $\mathrm{FiO}_{2}$ is more reliably delivered [7,15]. In some extreme cases the inspiratory flow demand may even exceed the flow capabilities of NHF, nonetheless NHF still performs better than COT [16].

\section{Airway hydration}

The conditioning of gases to body temperature $37^{\circ} \mathrm{C}$ and $100 \%$ humidified and delivered by NHF is known to enhance comfort for and tolerance by patients $[17,18]$. There are a series of other anticipated benefits, some of which are speculative:

- Desiccation of the airways may be avoided, thus supporting both the integrity of muco-ciliary function, and subsequent secretion clearance [19].
- Minimizing the bronchoconstriction associated with the delivery of cold, dry gas as delivered per COT [20].

- Relief of the metabolic burden of conditioning the inspired gas for vulnerable / high acuity patients.

\section{Therapeutic efficacy - clinical outcomes}

The therapeutic efficacy of NHF is rapidly evolving and driven both by the published evidence and the preference of clinicians. This therapy has been described in use in domiciliary settings and throughout the hospital on patients with differing clinical acuities and presentations.

\section{Respiratory failure \\ Respiratory failure type I}

Patients with respiratory failure (whatever the cause) need significant levels of respiratory support in order to avoid escalation. Traditionally the primary therapy has involved COT, NIV and or intubation. In 2010 the first observational study of NHF vs. COT was published, NHF was deemed superior for comfort and respiratory rate and $\mathrm{SpO}_{2}$ [21]. NHF has been found to be effective for patients with all severities of respiratory failure. Frat JP et al. [22] determined that neither NIV nor NHF decreased the rate of intubation among patients with hypoxemic ARF. In contrast, intubation rates did trend lower with NHF $(p=0.18)$. NHF use resulted in reduced mortality both within the ICU and up to 90 days. Of note the mortality rates with COT were $\times 2 \mathrm{NHF}(p=0.046)$, and with NIV $\times 2.5$ that of the NHF $(p=0.006)$. For the subgroup with $\mathrm{PaO}_{2}: \mathrm{FiO}_{2}<200 \mathrm{mmHg}$ a significantly lower 28 -day intubation rate $(p=0.009)$. NHF might therefore be considered as a first-line strategy in these patients, conversely NIV should be used cautiously as it may potentially worsen pre-existing lung injury [23].

\section{Respiratory failure type II}

There is some evidence to suggest that NHF therapy can support patients with some types of hypercapnic respiratory failure [24-27]. Patients with hypercapnic respiratory failure frequently present, and have been historically managed with NIV which is often not well tolerated. Millar J et al. [28] have reported the use of NHF for the successful management of a patient unable to tolerate NIV. Braunlich J et al. [9] evaluated the use of NHF both in healthy volunteers, and those with COPD, and idiopathic pulmonary fibrosis (IPF). Nasal High flow use was associated with an increased tidal volume in the COPD and IPF groups, whilst respiratory rate and minute volume decreased in all groups.

\section{Immunocompromised}

The needs of the immunocompromised patient are complex, with ARF being the most common complication. Careful selection of any intervention is vital NIV has been recommended as a first-line strategy despite the fact that studies have reported no benefit and even deleterious effects related to NIV. Retrospective reports of NHF use for these patients have suggested efficacy, however in a large randomized study NHF was not deemed superior to COT for rates of 28-day mortality [29]

\section{Post-extubation}

Effective post extubation respiratory support is vital to avoid reintubation and associated increases in ICU and in-hospital length of stay and mortality. In patients at high risk for reintubation NHF was noninferior to NIV [30]. In patients at low risk for reintubation NHF was superior to COT [31]. 


\section{Palliative care / do-not-intubate}

Nasal High Flow is emerging as an effective and ethical alternative to NIV for end of life care. Peters SG et al. [32] assessed the efficacy of NHF in patients with a do-not-intubate (DNI) and with hypoxemic respiratory failure. The comorbid conditions of those studied included: pulmonary fibrosis, pneumonia, COPD, cancer, hematologic malignancy, and CHF. The minority (18\%) required escalation to NIV, and $82 \%$ were maintained on NHF.

\section{Procedural sedation}

Hypoxemia is common during procedural sedation and supplemental oxygen often necessitated. Nasal High Flow has been used to provide a practical solution to both prevent and treat hypoxic events during bronchoscopy [33], gastroscopy [34], trans-esophageal echocardiogram [35], bronchoalveolar lavage [36], during dental surgery [37].

\section{Peri intubation}

Intubation of the unstable ICU patient is often associated with significant complications, the use of NHF in this setting is a current research priority. NIV can be applied to preoxygenate these patients however during laryngoscopy it must be removed, thus depriving a patient of $\mathrm{O}_{2}$. In contrast NHF cannula do not need to be removed and are able to deliver high flows and high concentrations of $\mathrm{O}_{2}$ throughout the procedure including the apneic period of tracheal intubation. Miguel-Montanes R et al. [38] compared the pre- and peri procedure oxygenation with non-rebreathing bag reservoir face mask and NHF during the intubation of 101 ICU patients, the authors concluded that NHF a could improve patient safety during intubation in ICU as the prevalence of severe hypoxemia was significantly reduced.

\section{Post-operative}

Differing forms of respiratory support have been used to reverse post-surgical respiratory complications. NIV is recommended for the curative and prophylactic management of ARF in post-operative patients in ICU. However recent studies suggest that NHF may have a role to play.

A large-scale randomized post cardiothoracic study suggested that NHF was equally good as NIV. No significant differences were seen for rates of treatment failure or ICU mortality $(p, 0.66)$ [17]. In a study of post lung resection patients, similar results were observed in the difference between pre-operative and postoperative 6-min walk test and spirometry between NHF and COT. Length of hospital stay was significantly lower in the NHF group and NHF reduced mortality both in the ICU and up to 90 days [39]. In a study of post abdominal surgery patients, no differences for postoperative hypoxemia, pulmonary complications or length of hospital stay were found between the two groups studied [40].

\section{Others}

There are many emerging / proposed applications for NHF. We await the conduct of further efficacy studies with appropriate and robust methodologies. The scope of the applications is very broad possibly reflecting the versatility of this therapy, for example: acute pulmonary oedema [41], acute heart failure [42], and cystic fibrosis [43].

\section{Contraindications for NHF}

The adoption of NHF therapy is now widespread. No absolute NHF contraindications have ever been reported in the literature, consequently the contraindications for NIV may be applied (Table 1) [44].

\section{Nasal high flow delivery}

There are three options available for the delivery of this therapy

1. An air/oxygen blender, a heated humidifier, a single heated circuit, and a dedicated nasal cannula. The flow source is the air/oxygen blender, the inspiratory fraction of oxygen $\left(\mathrm{FiO}_{2}\right)$ is set from 0.21 to 1.0 in flows of up to $60 \mathrm{~L} / \mathrm{min}$. Medical oxygen and air are required. The gas is heated and humidified with a humidifier and delivered through a heated circuit (Figure 1).

2. A specialist ventilator with a high flow mode, with a heated humidifier, a single heated circuit, and a dedicated nasal cannula. The flow source is the ventilator, the inspiratory fraction of oxygen $\left(\mathrm{FiO}_{2}\right)$ is set between 0.21 to 1.0 and flows of up to $60 \mathrm{~L} / \mathrm{min}$. Medical oxygen and air is required. The gas is heated and humidified with a humidifier and delivered through a heated circuit.

3. A specialist independent NHF flow source with an inbuilt heated humidifier, for example AIRVO ${ }^{m}$ Fisher \& Paykel Healthcare, a single heated circuit, and a dedicated nasal cannula. The flow source is the specialist unit, the inspiratory fraction of oxygen $\left(\mathrm{FiO}_{2}\right)$ is set from 0.21 to 1.0 with flows up to $60 \mathrm{~L} / \mathrm{min}$. Only medical oxygen is required air is entrained into the flow source. The gas is heated and humidified with an inbuilt humidifier and delivered through a heated circuit. This particular flow source may be used in the home and, or anywhere within a hospital setting (Figure 2).

The specialist nasal cannula (patient interface) are available in a range of sizes (neonates to adults), there is also an option of a tracheostomy interface. These specialist cannulas are designed for maximum comfort and stability. A major difference between NIV and NHF is the interface. NIV interfaces increase anatomical dead space, whereas NHF interfaces decrease dead space (Figure 3).

\section{Nasal high flow strategies for clinical applications}

Clinical outcome data for NHF has rapidly emerged, and so too are the reliable recommendations on practical applications of its use. This data combined with the data from the relevant physiological and mechanistic studies can inform clinical decision making around appropriate patient selection. Many physiological and mechanistic studies have demonstrated that the beneficial effects demonstrated are related to flow rate. Published studies, involving adults describe

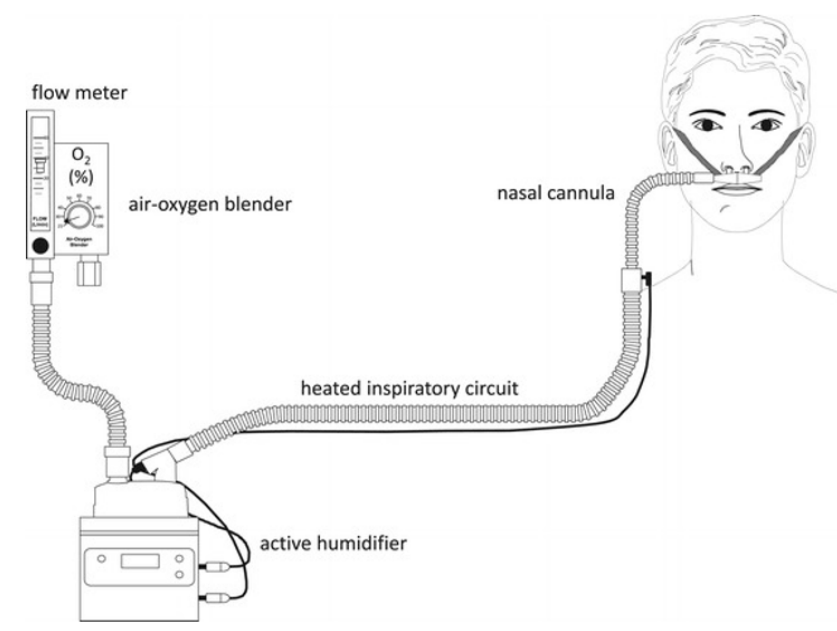

Figure 1. Delivery of high-flow nasal therapy via an air oxygen blender and heated humidifier 


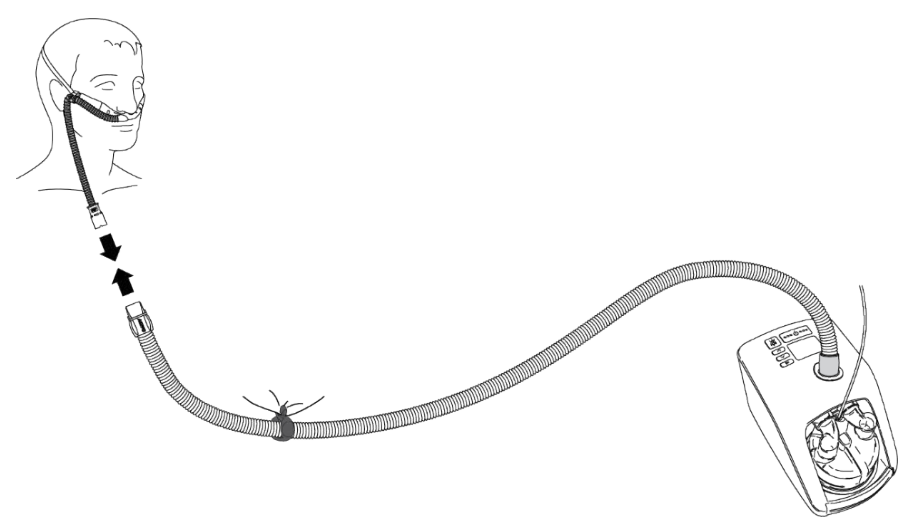

Figure 2. Delivery of high-flow nasal therapy via an independent flow source with built in humidifier and blender

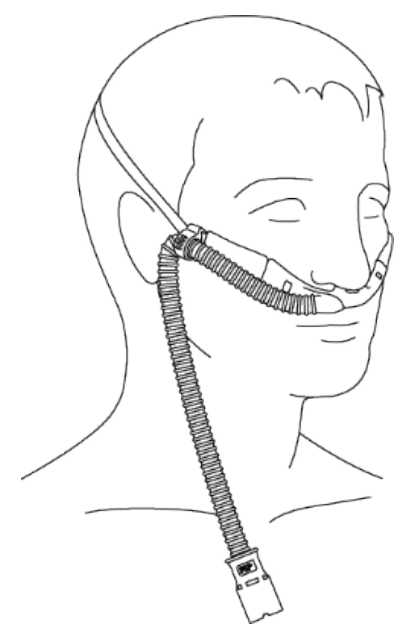

Figure 3. Adult high-flow interface

Table 1. Contraindications to NIV

\begin{tabular}{|c|l|}
\hline 1. & $\begin{array}{l}\text { Level of consciousness compromised } \\
\text { a. Unresponsive } \\
\text { b. Agitated } \\
\text { c. Uncooperative }\end{array}$ \\
\hline 2. & Claustrophobia \\
\hline 3. & Airway obstruction or unable to be maintained \\
\hline 4. & Craniofacial injury or malformation \\
\hline 5. & $\begin{array}{l}\text { Unstable hemodynamics } \\
\text { a. Shock } \\
\text { b. Intractable arrhythmia } \\
\text { c. Post-CPR }\end{array}$ \\
\hline 6. & Respiratory and or cardiac arrest either imminent or recent \\
\hline
\end{tabular}

starting flow rates of $20,25,35 \mathrm{~L} / \mathrm{min}$, but the majority start at $50 \mathrm{~L} /$ min [45]. Logic would then suggest that flow should be adjusted first and then $\mathrm{FiO}_{2}$ titrated to maintain a target oxygenation. Flow rates on commercially available devices differ but range from 5 to $60 \mathrm{~L} / \mathrm{min}$.

It would be reasonable to expect that an increase in flow and or $\mathrm{FiO}_{2}$ or would be expected to improve gaseous exchange, due to the reduced entrainment during inspiration. The requirement to up titrate or conversely down titrate is reliably demonstrated by changes in respiratory physiology particularly respiratory rate. An index known as the ROX index has been validated for use with patients with ARF and pneumonia, the index can identify patients at low risk for NHF failure [46]. The index is defined as the ratio of $\mathrm{SpO}_{2} / \mathrm{FiO}_{2}$ to respiratory rate.

\section{Escalation/ up titration in adults}

When aiming to increase $\mathrm{SpO}_{2}$, up titration of flow is preferable to raising $\mathrm{FiO}_{2}$. However, if $\mathrm{SpO}_{2}$ falls substantially below an acceptable target, increases in $\mathrm{FiO}_{2}$ can potentially raise the $\mathrm{PaO}_{2}$ more rapidly. Additional increases in flow rate can then be used to maintain targeted $\mathrm{SpO}_{2}$ while $\mathrm{FiO}_{2}$ is lowered to nontoxic levels.

Tolerance of continuous NHF for prolonged periods (many days) is high. As with all forms of respiratory support there are limitations and patients on this therapy should be adequately monitored. Just as described with NIV, Clinicians' may fail to recognize subtle signs of failure and a need to escalate care, which if delayed has consequences [47].

\section{De-escalation in adults}

When aiming to deescalate or wean from NHF it is recommended to wean the $\mathrm{FiO}_{2}$ first then the flow. A proposed weaning strategy involves first reducing $\mathrm{FiO}_{2}$ to $40 \%$, then flow in increments of $5 \mathrm{~L} /$ $\min [45]$.

\section{Research focus areas}

Much of the published research has been conducted within the high acuity arena such as the ICU. Further studies with appropriate and robust methodologies are needed to confirm the efficacy of NHF over other forms of respiratory support in specific populations and conditions in differing settings. This will assist in the development of clinical practice guidelines, and to provide an evidence base to potentially extend the scope of application of this therapy.

\section{References}

1. Mauri T, Turrini C, Eronia N, Grasselli G, Volta CA, et al. (2017) Physiologic Effects of High-Flow Nasal Cannula in Acute Hypoxemic Respiratory Failure. Am J Respir Crit Care Med 195: 1207-1215. [Crossref]

2. Itagaki T, Okuda N, Tsunano Y, Kohata H, Nakataki E, et al. (2014) Effect of highflow nasal cannula on thoraco abdominal synchrony in adult critically ill patients. Respir Care 59: 70-74. [Crossref]

3. Mündel T, Feng S, Tatkov S, Schneider H (2013) Mechanisms of nasal high flow on ventilation during wakefulness and sleep. J Appl Physiol (1985) 114: 1058-1065. [Crossref]

4. Riera J, Pérez P, Cortés J, Roca O, Masclans JR, et al. (2013) Effect of high-flow nasal cannula and body position on end-expiratory lung volume: a cohort study using electrical impedance tomography. Respir Care 58: 589-596. [Crossref]

5. Spence CJT, Buchmann NA, Jermy MC (2012) Unsteady flow in the nasal cavity with high flow therapy measured by stereoscopic PIV. Exp Fluids 52: 569-579.

6. Frizzola M, Miller TL, Rodriguez ME, Zhu Y, Rojas J, et al. (2011) High-flow nasal cannula: impact on oxygenation and ventilation in an acute lung injury model. Pediatr Pulmonol 46: 67-74. [Crossref]

7. Sim MAB, Dean P, Kinsella J, Black R, Carter R, et al. (2008) Performance of oxygen delivery devices when the breathing pattern of respiratory failure is simulated. Anaesthesia 63: 938-940. [Crossref]

8. Groves N, Tobin A (2007) High flow nasal oxygen generates positive airway pressure in adult volunteers. Aust Crit Care 20: 126-131. [Crossref]

9. Bräunlich J, Beyer D, Mai D, Hammerschmidt S, Seyfarth HJ, et al. (2012) Effects of nasal high flow on ventilation in volunteers, COPD and idiopathic pulmonary fibrosis patients. Respiration 85: 319-325. [Crossref]

10. Parke R, McGuinness S, Eccleston M (2009) Nasal high-flow therapy delivers low level positive airway pressure. Br J Anaesth 103: 886-890. [Crossref]

11. Corley A, Caruana LR, Barnett AG, Tronstad O, Fraser JF (2011) Oxygen delivery through high-flow nasal cannulae increase end-expiratory lung volume and reduce respiratory rate in post-cardiac surgical patients. Br J Anaesth 107: 998-1004. [Crossref]

12. Parke RL, Eccleston ML, McGuinness SP (2011) The effects of flow on airway pressure during nasal high-flow oxygen therapy. Respir Care 56: 1151-1155. [Crossref] 
13. Spence KL, Murphy D, Kilian C, McGonigle R, Kilani RA (2007) High-flow nasal cannula as a device to provide continuous positive airway pressure in infants. $J$ Perinatol 27: 772-775. [Crossref]

14. Saslow JG, Aghai ZH, Nakhla TA, Hart JJ, Lawrysh R, et al. (2006) Work of breathing using high-flow nasal cannula in preterm infants. $J$ Perinatol 26: $476-480$. [Crossref]

15. Wagstaff TAJ, Soni N (2007) Performance of six types of oxygen delivery devices at varying respiratory rates. Anaesthesia 62: 492- 503. [Crossref]

16. Ritchie JE, Williams AB, Gerard C, Hockey H (2011) Evaluation of humidified nasal high-flow oxygen system, using oxygraphy, capnography and measurement of upper airways pressure. Anesth Intensive Care 39: 1103 - 1110. [Crossref]

17. Stéphan F, Barrucand B, Petit P, Rézaiguia-Delclaux S, Médard A, et al. (2015) HighFlow Nasal Oxygen vs Noninvasive Positive Airway Pressure in Hypoxemic Patients After Cardiothoracic Surgery: A Randomized Clinical Trial. JAMA 313: 2331-2339. [Crossref]

18. Maggiore SM, Idone FA, Vaschetto R, Festa R, Cataldo A, et al. (2014) Nasal highflow versus Venturi mask oxygen therapy after extubation. Effects on oxygenation, comfort, and clinical outcome. Am J Respir Crit Care Med 190: 282 - 288. [Crossref]

19. Hasani A, Chapman TH, McCool D, Smith RE, Dilworth JP, et al. (2008) Domiciliary humidification improves lung mucociliary clearance in patients with bronchiectasis. Chron Respir Dis 5: 81 - 86. [Crossref]

20. Williams R, Rankin N, Smith T, Galler D, Seakins P (1996) Relationship between the humidity and temperature of inspired gas and the function of the airway mucosa. Crit Care Med 24:1920 - 1929. [Crossref]

21. Roca O, Riera J, Torres F, Masclans JR (2010) High-flow oxygen therapy in acute respiratory failure. Respir Care 55: 408 - 413. [Crossref]

22. Frat JP, Thille AW, Mercat A, Girault C, Ragot S, et al. (2015) High-flow oxygen through nasal cannula in acute hypoxemic respiratory failure. N Engl J Med 372: 2185 2196. [Crossref]

23. Frat JP, Coudroy R, Thille AW (2018) Non-invasive ventilation or high-flow oxygen therapy: When to choose one over the other? Respirology 24: 724-731. [Crossref]

24. Bräunlich J, Kohler M, Wirtz H (2016) Nasal highflow improves ventilation in patients with COPD. Int J Chron Obstruct Pulmon 11: 1077-1085. [Crossref]

25. Atwood CW Jr, Camhi S, Little KC, Paul C, Schweikert H, et al. (2017) Impact of Heated Humidified High Flow Air via Nasal Cannula on Respiratory Effort in Patients with Chronic Obstructive Pulmonary Disease. Chronic Obstr Pulm Dis 4: 279-286. [Crossref]

26. Fraser JF, Spooner AJ, Dunster KR, Anstey CM, Corley A (2016) Nasal high flow oxygen therapy in patients with COPD reduces respiratory rate and tissue carbon dioxide while increasing tidal and end-expiratory lung volumes: a randomised crossover trial. Thorax 71: 759-761. [Crossref]

27. Pisani L, Fasano L, Corcione N, Comellini V, Musti MA (2017) Change in pulmonary mechanics and the effect on breathing pattern of high flow oxygen therapy in stable hypercapnic COPD. Thorax 72: 373 - 375. [Crossref]

28. Millar J, Lutton S, O'Connor P (2014) The use of high-flow nasal oxygen therapy in the management of hypercarbic respiratory failure. Ther Adv Respir Dis 8: 63-64. [Crossref]

29. Azoulay E, Lemiale V, Mokart D, Nseir S, Argaud L, et al. (2018) Effect of HighFlow Nasal Oxygen vs Standard Oxygen on 28-Day Mortality in Immunocompromised Patients with Acute Respiratory Failure: The HIGH Randomized Clinical Trial. JAMA 320: 2099-2107. [Crossref]

30. Hernández G, Vaquero C, González P, Subira C, Frutos-Vivar F, et al. (2016) Effect of postextubation high-flow nasal cannula vs conventional oxygen therapy on reintubation in low-risk patients: a randomized clinical trial. JAMA 315: 1354-1361. [Crossref]
31. Hernández G, Vaquero C, Colinas L, Cuena R, González P, et al. (2016) Effect of postextubation high-flow nasal cannula vs noninvasive ventilation on reintubation and postextubation respiratory failure in high-risk patients: a randomized clinical trial. JAMA 316: 1565 - 1574. [Crossref]

32. Peters SG, Holets SR, Gay PC (2013) High-flow nasal cannula therapy indo-notintubate patients with hypoxemic respiratory distress. Respir Care 58: $597-600$ [Crossref]

33. Lucangelo U, Vassallo FG, Marras E, Ferluga M, Beziza E, et al. (2012) High-flow nasal interface improves oxygenation in patients undergoing bronchoscopy. Crit Care Res Pract 2012: 506382. [Crossref]

34. La Combe B, Messika J, Fartoukh M, Ricard JD (2016) Increased use of high-flow nasal oxygen during bronchoscopy. Eur Respir J 48: 590-592. [Crossref]

35. Sakazaki R, Suzuki T, Ikeda N (2019) High-Flow Nasal Cannula Oxygen SupportedTransesophageal Echocardiography Under Sedation in a Respiratory Compromised Patient. J Cardiothorac Vasc Anesth 33: 255- 256. [Crossref]

36. Kim EJ, Jung CY, Kim KC (2018) Effectiveness and Safety of High-Flow Nasa Cannula Oxygen Delivery during Bronchoalveolar Lavage in Acute Respiratory Failure Patients. Tuberc Respir Dis (Seoul) 81: 319-329. [Crossref]

37. Sago T, Harano N, Chogyoji Y, Nunomaki M, Shiiba S, et al. (2015) A nasal highflow system prevents hypoxia in dental patients under intravenous sedation. J Oral Maxillofac Surg. 73: 1058-1064. [Crossref]

38. Miguel-Montanes R, Hajage D, Messika J, Bertrand F, Gaudry S, et al. (2015) Use of high-flow nasal cannula oxygen therapy to prevent desaturation during tracheal intubation of intensive care patients with mild-to-moderate hypoxemia. Crit Care Med 43: 574-583. [Crossref]

39. Ansari BM, Hogan MP, Collier TJ, Baddeley RA, Scarci M, et al. (2016) A Randomized Controlled Trial of High-Flow Nasal Oxygen (Optiflow) as Part of an Enhanced Recovery Program After Lung Resection Surgery. Ann Thorac Surg 101 459 - 446. [Crossref]

40. Futier E, Paugam-Burtz C, Godet T, Khoy-Ear L3, Rozencwajg S, et al. (2016) Effect of early postextubation high-flow nasal cannula vs conventional oxygen therapy on hypoxaemia in patients after major abdominal surgery: a French multicentre randomized controlled trial (OPERA). Intensive Care Med 42: 1888-1898. [Crossref]

41. Makdee O, Monsomboon A, Surabenjawong U, Praphruetkit N, Chaisirin W, et al (2017) High-flow nasal cannula versus conventional oxygen therapy in emergency department patients with cardiogenic pulmonary edema: a randomized controlled trial. Ann. Emerg. Med 70: 465-472. [Crossref]

42. Carratalá Perales JM, Llorens P, Brouzet B, Albert Jiménez AR, Fernández-Cañadas JM, et al. (2011) High-flow therapy via nasal cannula in acute heart failure. Rev Esp. Cardiol 64: 723-725.[Crossref]

43. Sklar MC, Dres M, Rittayamai N, West B, Grieco DL, et al. (2018) High-flow nasal oxygen versus noninvasive ventilation in adult patients with cystic fibrosis: A randomized crossover physiological study. Ann Intensive Care 8: 85. [Crossref]

44. Jaber S, Chanques G, Jung B (2010) Postoperative Noninvasive Ventilation. Anesthesiology 112: 453-461. [Crossref]

45. Ischaki E, Pantazopoulos I, Zakynthinos S (2017) Nasal high flow therapy: A novel treatment rather than a more expensive oxygen device. Eur Respir Rev 26: 170028. [Crossref]

46. Roca O, Messika J, Caralt B, García-de-Acilu M, Sztrymf B, et al. (2016) Predicting success of high-flow nasal cannula in pneumonia patients with hypoxemic respiratory failure: The utility of the ROX index. J Crit Care 35:200-205. [Crossref]

47. Kang BJ, Koh Y, Lim CM, Huh JW, Baek S, et al. (2015) Failure of high-flow nasal cannula therapy may delay intubation and increase mortality. Intensive Care Med 41: 623-632. [Crossref]

Copyright: (C2019 Donnell JO. This is an open-access article distributed under the terms of the Creative Commons Attribution License, which permits unrestricted use, distribution, and reproduction in any medium, provided the original author and source are credited. 